\title{
A Brief Analysis on the Application of Calligraphy in Package Design
}

\author{
Yuanyuan Cai \\ College of Humanities \\ Yantai Nanshan University \\ Yantai, China
}

\begin{abstract}
Calligraphy is an abstract art, plays an important part in package design. The application of calligraphy in package design is also decided by its nature and characteristics. Therefore, to apply calligraphy in package design properly, package designers must experience life deeply and value investigation to cultivate artistic culture. Only in this way can we rich their design conception and design language, and make our works more charming.
\end{abstract}

Keywords — calligraphy; package design; manifestation form

\section{INTRODUCTION}

Character is a crucial visual symbol for people to convey message, it is also the only one that can express commodity information independently. Not only does Character express commodity information exactly, but it also popularize and beautify the commodity. This characteristic decides the two roles of Chinese character that to carry language contents and to manifest visual images, so Chinese character is both tangible media for language record and the manifestation for structure features of strokes and unique temperament by kinds of different writing forms to show certain vision individuality. Calligraphy is the perfect demonstration of this vision individuality.

\section{APPLICATION OF CALLIGRAPHY IN PACKAGE DESIGN}

In eastern culture, calligraphy is one of the pithiest and most respected art form and one miracle of character writing. It has a centuries-old historical tradition. It is perfect match of artistic skills and traditional Confucianism. Soft writing brush is the best choice for writing, with the match of certain paper and ink, the character changes into thick, pale, dry, wet, slow and fast writing, improving simple skills into a highly creative art, enriching skills with abundant aesthetic connotation, further developing them a calligraphy spirit with a high level. Of course, the characters are totally different from stylized description as well as mechanical and regulated character combination of print form because of their specific writing ways, giving incomparable creation freedom to manifestation form. While, the freedom makes strokes an actual manifestation of line art from the very beginning. Not relying on color, shadow or physical block, it is absolutely made up of lines, the connotation showed by stipple appearance is implicit, blear, vivid and ample. With the aid of pen's move on the paper, the strokes are written at one stretch, lines on paper here are not just lines with moving, they are also lines moving with dynamic and rhythm, they are symbols recording time on books. Therefore, the beauty of calligraphy is not manifested by individual word, but by infinite changes, lively atmosphere and flowing rhythm between lines and words.

After thousands of years' depositing, calligraphy itself is one heritage of culture. Design art is a social and cultural activity, and it shows in both physical form and invisible cultural spirit, because package art itself is a cultural medium and the carrier of culture inheritance. First of all, package is a capacity emerged along with creative activities and creative methods of people. In the heritance of national culture, we can fully display the unification of conventionality and modernity; Second, design culture is a dynamic system. It develops constantly, which produce influence in people's productivity and life virtually, becoming the focus people invisibly. As an information transmission medium, package design has an independent meaning in transfer of cultural information, becomes physical form of culture. In the unification of form and content, In addition to meet its original function, package design keeps the print of national culture in plane and three-dimensional space inconsciently.

In China, our ancestors start to apply calligraphy in package design early, for instance the signboard making of kinds of shops. By connecting design of character with connotation of commodity, the expression of brands can be better. At present, Chinese designers are attempting to apply calligraphy in package design. The 2010 world expo emblem was designed on the basic of Chinese character "shi", which implies three people embrace together, a symbol of the "you, me, him" all mankind, expresses the 2010 world expo idea understanding, communication, happy reunion and cooperation, indicates Chinese national spirit-worship harmony and unity. The calligraphy "shi" is different in approach but equally satisfactory in result with The Beijing 2008 Olympic Games emblem - the seal cutting "jing" and they add radiance and beauty to each other. The station caption of Heilongjiang TV channels is "long" written in semi-cursive script, its jubilant and dancing body shows masculine beauty, and manifests that the descendants of the dragon (metaphor for the Chinese nation) have a good spiritual state whether in low ebb or climax. So we can say 
that as an effective factor and symbol, Chinese character wins successively by shape and connotation.

The application of calligraphy in package design is a good way to manifest national culture. This is also request of the ages and Chinese package design development. I think Chinese package design should absorb calligraphy and update multidirectionally along with the development of times whether in mode of thinking, mode of value perception or mode of social organization in order to build a new package design cultural system with national characteristics and epochal character because this is the request of the ages and the necessary road of history, it is the key for Chinese package design standing on the world advanced level. While, only something with national character should belong to world class, calligraphy is Chinese unique cultural property, which is also the request of the development of socialist market economy with Chinese characteristics. With the development of society and the improvement of science technology, Standard and unified mass package design methods will be increasingly sidelined because they are boring, dull and all in the same key, they are lack of vitality and diversity. In recent years, some excellent works have been produced along with people's the increasing attention on calligraphy, these make consumers enjoy the beauty of calligraphy and have a high collection value. Take our Chinese package design of tea-leaves for example, the designers often write traditional "cha" on the light green base, add a cup of water at the bottom, which both decorate the design well and closely connect the commodity with its nature. Another example is the cover design of books with high value of traditional culture, their names are usually written by calligraphers, then beautify them to improve cultural connotation. In some package of local flavor snacks and convenient food, words are arranged variously, pursuing lively, jumping, and dynamic performance effect. While in the package of electronic products, designers often use simple, vogue and marked words matched with flexible arrangement methods to display era characteristics and hightech features of commodity.

At the same time, the application of calligraphy in package design is also decided by nature and characteristics of the commodity itself. Therefore, to apply calligraphy in package design properly, package designers must experience life deeply and value investigation to cultivate artistic culture. Only in this way can we rich their design conception and design language, and make our works more charming. For example, calligraphy used in commodities for male should be rough and heroic while that used in female commodities should be elegant and feminine. Calligraphy used in commodities for children should be innocent and naïve, vivid and active, lively and exultant, should have clear rhythm, and should give people a sense of brimming over with vigor and vitality. Traditional old style is famous and precious with antique beauty, which is suitable for package design of antique, jades and native products. However, roman type gives people a sense of sobriety and balance, which is suitable for various mechanical and electrical products, light industrial goods, food and beverages. Seal character used in New Year card, invitation card, badge and picture makes people feel graceful and generous, primitive and elegant. Cursive script and running script, clever and lively, easily written, are mainly used in package of cigarettes and wine, books and advertising posters.

Of course, the application of calligraphy in the package design has more complex requirements. To use calligraphy to reflect the traditional culture in modern packaging design to enrich it with traditional verve, pursue innovation and retains embodiment of the traditional style at the same time, making cultural heritage more vigor. This requires designers to create new forms on the basis of absorbing, combined with the times, make traditional culture more modern, and reach the real communion of traditional culture and modern packaging design concept.

\section{CONCLUSION}

Chinese package design should absorb calligraphy and update multidirectionally along with the development of times whether in mode of thinking, mode of value perception or mode of social organization in order to build a new package design cultural system with national characteristics and epochal character because this is the request of the ages and the necessary road of history, it is the key for Chinese package design standing on the world advanced level. There is no doubt that designers can use calligraphy in design of package, decoration, logo and environment in modern society, which also called for a higher request on designers to some extent, that is, the designers should value the learning of calligraphy, and be consist on exercising calligraphy basic skills, keep on discussion and application of calligraphy and make the abstract calligraphy more charming in modern design.

\section{REFERENCES}

[1] Discussion on Constitution of Calligraphic Art, Baidu Library, April 2014.

[2] Liu Juan. Function of Research on Formal Beauty of Chinese Characters for the Design on Modern Plane Graphic, June 2007. 